\title{
A Group Decision-Making Approach Based on DST and AHP for New Product Selection under Epistemic Uncertainty
}

\author{
Chong Wu ${ }^{D},{ }^{1}$ Zijiao Zhang ${ }^{D},{ }^{2}$ and Wei Zhong ${ }^{2}$ \\ ${ }^{1}$ School of Management, Harbin Institute of Technology, Harbin 150000, China \\ ${ }^{2}$ School of Economics and Management, Chuzhou University, Chuzhou 239000, China \\ Correspondence should be addressed to Zijiao Zhang; zzijiaojiayou@163.com
}

Received 2 March 2019; Revised 27 April 2019; Accepted 2 June 2019; Published 19 June 2019

Guest Editor: Love Ekenberg

Copyright (c) 2019 Chong Wu et al. This is an open access article distributed under the Creative Commons Attribution License, which permits unrestricted use, distribution, and reproduction in any medium, provided the original work is properly cited.

\begin{abstract}
Selecting the most appropriate new product(s) is regarded as a critical decision which greatly influences the development of manufacturing enterprises. In order to improve the accuracy of selection, more experts are required to be invited to predict key indicators for new products selection. Due to limited knowledge, experts use fuzzy numbers more confidently than using numerical values in the prediction. Therefore, new product selection is a multiattribute group decision-making process under epistemic uncertainty. The purpose of this paper is to introduce a new hybrid decision-making approach based on Analytic Hierarchy Process (AHP) and Dempster-Shafer Theory (DST) to evaluate and select a new product. AHP and DST are used in weight determination to improve the accuracy and objectivity. In addition, this paper proposes that DST is a proper mathematical framework to deal with the epistemic uncertainty on the indicators of new product scheme selection. In particular, the initial assessments from experts are disassembled and then combined into the evidence information. By setting confidence degree, reliability function and likelihood function are used to evaluate and rank new products. A case study in a home appliance manufacturer is provided to illustrate the proposed hybrid approach and demonstrate its applicability.
\end{abstract}

\section{Introduction}

As the market is increasingly competitive, it is more important for enterprises to choose an appropriate new product. Good new products can bring hope to dying enterprises. On the contrary, bad schemes make prosperous enterprises fail. There are eight phases typically in new product development (NPD), namely, idea generation, idea screening, concept development and testing, marketing strategy development, business analysis, product development, market testing, and commercialization. Idea screening, also known as new product selection, is choosing the best one from a number of schemes, which is the most important task for NPD. Therefore, the research on new product selection is of vital significance.

It is difficult to choose an optimal scheme from many designs. The main reasons are as follows. First of all, there are many factors to be considered while making decision, such as product performance, market potential, project risk, and customer demand. Secondly, because decision making is for the future, the impact factors are full of uncertainty. That is why accurate number is difficult to use to represent factors. Last but not least, these factors are estimated by experts on the basis of their past experience and personal preferences, which leads to different evaluations by different experts. If only one expert is invited for evaluation, the results would be influenced by his own experience and preferences. If more than one expert is invited, different estimations would be obtained. How to deal with these differences is an important problem to be solved. Therefore, new product selection is a problem worthy for studying.

Based on the first point, it is very necessary to select several indicators to help the researchers make decisions. Therefore, the study is a multiple criteria decision-making (MCDM) process. Based on the second point, fuzzy number is advised to express indicators which are difficult to express by accurate number. And a fuzzy set should be used in the study of new product selection. In order to eliminate the impact of individual preferences and experience, a number of experts would be invited to estimate indicators. Thus, a 
conclusion can be drawn that it is a group decision-making problem. That is to say, new product selection is a fuzzy multiattribute group decision-making model.

There are three key problems to deal with in this issue. The first one is how to judge the relationship between those indicators. That is to say, which indicators are more important and which can be slightly sacrificed. Therefore, weight determination is the first key point in the model. The second question is how to calculate and judge the attributes expressed by fuzzy numbers, so as to carry out comprehensive evaluation. The last one is how to deal with these differences on indicators estimated by various experts and to get attribute values more accurately. In a word, it is uneasy to select an optimal scheme from multiple designs.

The purpose of this paper is to present a group decisionmaking approach based on Dempster-Shafer Theory (DST) and Analytic Hierarchy Process (AHP) for new product selection under epistemic uncertainty. Firstly, many experts are asked to grade indexes according to scale. And AHP is applied to calculate attribute weights. Due to different experiences and preferences, weights given by different experts are various. And DST is used for the final weight to eliminate the difference. In addition, DST is used as a proper mathematical framework to deal with the epistemic uncertainty. By building reliability function and likelihood function, comprehensive evaluation of new scheme is carried out. Finally, the validity of this method is verified by a case study. The structure of this paper is as follows: the second part is related work; the third part is an introduction to Dempster-Shafer Theory; the fourth section is the establishment of the evaluation model, and the fifth section is case study.

\section{Related Work}

NPD is the foundation for enterprises to survive and develop. Therefore, a key task for top management is to choose appropriate new products. When evaluating product plans, top management should take many factors into consideration and prediction, such as market trend, product market competitiveness, product cost, and technical requirements. The work of new product evaluation is very important and complex for enterprises. It is also an important topic for researchers. Therefore, many researchers have proposed different tools or methods to evaluate new product schemes.

(i) Risk assessment: Katie et al. [1] proposed a risk identification framework from system perspectives, which can be used to assess risks quantitatively of new products. Patil et al. [2] predicted business risks at the beginning of new product design and established a risk framework. Fang and Marle [3] designed a way to identify inherent risks and cross risks of projects according to the direction of risk communication. Mohit [4] designed a risk network corresponding to different functional organizations based on Bayesian network method to measure risks of all new projects.

(ii) Key factors: Kim et al. [5] summarized key factors in NPD by studying cases of developing new products in virtual teams of SME. Cooper et al. [6] identified the critical factors that set the most successful firms apart from their competitors by benchmarking at the company or macro level, to ensure that resources are allocated appropriately. Lam et al. [7] used AHP to study the most important 13 factors in the process of new product development from the perspective of conflict management. Cunha [8] studied the key success factors by summarizing the empirical and conceptual studies of NPD in the past 30 years.

(iii) Quality function deployment (QFD): Lowe et al. [9] developed a new product evaluation tool based on QFD to evaluate potential products for an innovative metal forming process. Hanumaiah et al. [10] built a rapid hard tooling process selection though QFD and AHP methodology. Lee [11] selected the critical factors though Fuzzy Delphi method and constructed houses of quality for QFD in NPD. Zhang Xuefeng [12] proposed an integrated approach based on QFD and DEA to ensure user collaboration which has been recognized as a critical factor in successful product development. Yu L, Wang L, and Bao Y [13] proposed a new product evaluation approach based on QFD integrated IVIF and CI.

(iv) Artificial neural network: Thieme et al. [14] evaluated and chose the new plan by constructing the neural network model. HO and Tsai [15] proposed a new method based on structural equation model (SEM) and adaptive neural fuzzy inference system (ANFIS) to predict the effect of value process quality on the performance of NPD.

(v) AHP/ANP and TOPSIS: Lin et al. [16] constructed a method based on AHP and TOPSIS to identify customer requirements and design features, so as to evaluate design schemes. Shyur et al. [17] used ANP to determine evaluation criteria and weights and used the improved TOPSIS to arrange alternative designs. Chiuh et al. [18] presented a fuzzy analytic network process (FANP) for solving the product selection. Akkaya et al. [19] constructed a new method based on fuzzy AHP and fuzzy MOORA for industrial engineering sector choosing problem. Joshi and Kumar [20] held that, in the process of group decision-making, the interaction of decision criteria and concept uncertainty has a great influence on the membership function.

(vi) Fuzzy set: When hen solving the optimal new product plan, some attributes are hard to be expressed numerically. Many scholars have adopted fuzzy sets, for example, Carrera Diego A et al. [21] and Chen H. $\mathrm{H}$ et al. [22]. On the basis of considering the favorable and unfavorable factors, Lin and Yang [23] calculated the fuzzy attractiveness and determined portfolio selection problems. Kit et al. [24] proposed a forward selection based on fuzzy regression (FS-FR) to correlate engineering characteristics with consumer preferences regarding a new product. Büyüközkan $G$ 
et al. [25] constructed a multicriteria group decisionmaking approach based on intuitionist fuzzy TOPSIS for smart phone selection. Kumru et al. [26] proposed a new hybrid approach for multicriteria decisionmaking problems through combining intuitionist fuzzy analytic hierarchy process and intuitionist fuzzy multiobjective optimization by ratio analysis.

(vii) Group decision making: Ren et al. [27] used fuzzy information and group decision analysis method to construct an extension method of fuzzy measurement, so as to solve the problem of evaluation and selection. Ebrahimnejad S. et al. [28] introduced a new hierarchical multi criteria group decisionmaking method to solve the optimal selection of new product design alternatives. What is more, it proposed sets to evaluate and analyze new products. Lo C. C. et al. [29] and Chung et al. [30] used both group decision-making and fuzzy number applied an axiomatic design method using fuzzy linguistic to make multiattribute group decision. Tuzkaya [31] suggested that IFCI operators should adopt MCDM method, take advantage of the interaction between fuzziness of decision environment and decision criteria, and combine supplier evaluation processes. Gülçin Büyüközkan et al. [32] presented a creative approach to evaluate the smart medical device selection process in a group decision-making with intuitionistic fuzzy set based on fuzzy choquet integral. Mousavi et al. [33] adopted a hierarchical group decision-making approach to new product selection based on VIKOR.

(viii) Other methods: Sarı et al. [34] used fuzzy Monte Carlo simulation to evaluate new product investment plans, so as to select the best. Huanghong et al. [35] adopted computational intelligence techniques for New Product Design. Wang wenpei [36] presented a 2-tuple fuzzy linguistic computing approach to deal with heterogeneous information and information loss problems during the processes of subjective evaluation integration in NDP. Gülçin et al. [37] identified the decision points in the NPD process and the uncertainty factors affecting those points and proposed an integrated approach based on fuzzy logic to shape the decisions.

Although many scholars put forward different methods for new product scheme selection from different perspectives, there are some external conditions which are not taken into consideration in these methods. Firstly, the majority of scholars hold the view that new product scheme selection is a multiattribute decision-making (MADM) problem. And many MADM methods are used for new product selection. The MAMD methods differ in different fields. Some MADM methods are used to solve one specific problem and they are not suitable for other problems. These MADM methods can be divided into two categories. One is compensatory methods, such as AHP, TOPSIS, and VIKOR. The other is noncompensatory methods, such as Dominance, Max-min, Conjunctive-Satisfying, and Elimination methods. When choosing a new product, some attributes considered are cross-cutting. So, it is more appropriate to use compensatory MADM approach. Each compensatory method has its advantages and disadvantages. Compared with TOPSIS and VIKOR, AHP is more suitable for determining index weight in NPD. This is found in many literatures. Attribute weights is very important for the final scheme selection. It may be inaccurate to judge the importance of each indicator only by personal knowledge and experience. Inviting multiple experts to evaluate indicators weights and dealing with different weights are seldom mentioned in previous literatures. So, in this paper, an approach based on DST and AHP is proposed to solve this problem.

In addition, the attribute values of new products are estimated for future, which makes it difficult for experts to express the attributes of the new scheme numerically relying on limited knowledge and experience. Experts use fuzzy number more confidently compared to using specific value to represent the attributes of new schemes. In order to improve the accuracy of prediction, some scholars use hesitant fuzzy sets. However, new products from R\&D to production and sales involve many links, and it is difficult for an expert to grasp all the information. More experts should be invited to evaluate the future performance of new products in order to improve the accuracy of the estimations. However, the research on this aspect has hardly been mentioned in previous papers. The fact that various experts would have different knowledge leads to different results given by different experts to the same attribute of the same design. In general, the best choice from new product plans is a fuzzy multicriteria group decision-making problem and an evaluation approach based on DST is proposed.

\section{Dempster-Shafer Theory}

DST was put forward by Professor P. Dempster of Harvard University. Glenn Shafer, a student of Professor P. Dempster, has further developed evidence theory and constructed a mathematical method for calculating uncertainty. This method is mainly used in information fusion, expert system, intelligence analysis, legal case analysis, and multiattribute decision-making. This method (Certa et al. [38]; Shafer [39]; Li dawei et al. [40]) is based on three different measures, namely, Basic Probability Assignment (BPA), Belief Measure (BEL), and Plausibility Measure (PL).

Definition 1 (basic probability assignment (BPA)). Suppose U is the frame of discernment. BPA on frame of discernment is a function $\mathrm{m}$ of $2^{\mathrm{U}} \longrightarrow[0,1]$. On BPAs the following assumptions hold:

$$
\begin{aligned}
\mathrm{m}(\emptyset) & =1 \\
\sum_{\mathrm{A} \subseteq \mathrm{U}} \mathrm{m}(\mathrm{A}) & =1 \\
\mathrm{~m}(\mathrm{~A}) & >0
\end{aligned}
$$

Definition 2 (belief function). Belief Function is the sum of BPAs for all subsets of A. On the frame of discernment $U$, 
reliability function based on BPA is expressed by Bel (A), and its calculation formula is as follows:

$$
\operatorname{Bel}(\mathrm{A})=\sum_{\mathrm{B} \subseteq \mathrm{A}} \mathrm{m}(\mathrm{B})
$$

Definition 3 (plausibility function). Plausibility Function is the sum of BPAs of all subsets intersecting with A. On the frame of discernment $\mathrm{U}$, plausibility function based on BPA is expressed by $\mathrm{Pl}(\mathrm{A})$, and its calculation formula is as follows:

$$
\operatorname{Pl}(\mathrm{A})=\sum_{\mathrm{B} \cap \mathrm{A} \neq \emptyset} \mathrm{m}(\mathrm{B})
$$

Definition 4 (trust intervals). The Trust Interval of $\mathrm{A}$ is denoted as $[\operatorname{Bel}(\mathrm{A}), \mathrm{Pl}(\mathrm{A})] \cdot \operatorname{Bel}(\mathrm{A})$ is the lower bound of the Trust Interval, and $\mathrm{Pl}(\mathrm{A})$ is the upper bound. For example, the trust interval of event $\mathrm{A}$ is $(0.25,0.85)$. The probability that $\mathrm{A}$ is true is 0.25 , the probability that $\mathrm{A}$ is false is 0.15 , and the probability that $\mathrm{A}$ is uncertain is 0.6

Definition 5 (Dempster aggregation rule). DST can be used to integrate evidences from multiple independent sources. There are a finite number of mass functions on the recognition framework $U$, namely, $m_{1}, m_{2}, m_{3}, m_{4}, \ldots m_{n}$. The aggregation rules are as follows:

$$
\begin{aligned}
& \left(\mathrm{m}_{1} \oplus \mathrm{m}_{2} \oplus \cdots \oplus \mathrm{m}_{\mathrm{n}}\right)(\mathrm{A}) \\
& =\frac{1}{\mathrm{~K}} \sum_{\mathrm{A}_{1} \cap \mathrm{A}_{2} \cap \cdots \cap \mathrm{A}_{\mathrm{n}}=\mathrm{A}} \mathrm{m}_{1}\left(\mathrm{~A}_{1}\right) \cdot \mathrm{m}_{2}\left(\mathrm{~A}_{2}\right) \cdots \mathrm{m}_{\mathrm{n}}\left(\mathrm{A}_{\mathrm{n}}\right) \\
& \mathrm{K}=\sum_{\mathrm{A}_{1} \cap \mathrm{A}_{2} \cap \cdots \cap \mathrm{A}_{\mathrm{n}} \neq \emptyset} \mathrm{m}_{1}\left(\mathrm{~A}_{1}\right) \cdot \mathrm{m}_{2}\left(\mathrm{~A}_{2}\right) \cdots \mathrm{m}_{\mathrm{n}}\left(\mathrm{A}_{\mathrm{n}}\right) \\
& =1-\sum_{\mathrm{A}_{1} \cap \mathrm{A}_{2} \cap \cdots \cap \mathrm{A}_{\mathrm{n}}=\emptyset} \mathrm{m}_{1}\left(\mathrm{~A}_{1}\right) \cdot \mathrm{m}_{2}\left(\mathrm{~A}_{2}\right) \cdots \mathrm{m}_{\mathrm{n}}\left(\mathrm{A}_{\mathrm{n}}\right)
\end{aligned}
$$

$\mathrm{K}$ is called normalization factor, and the value of $1-\mathrm{K}$ reflects the degree of evidence conflict.

\section{A New FMCGDM Approach Model Based on AHP and DST}

In order to study the complex problem in NPD, this paper focuses on the FMCGDM (fuzzy multiple criteria group decision-making). In this paper, a new FMCGDM approach based on DST and AHP is proposed. This method consists of four important parts. Firstly, an index system for new product selection is constructed, and attribute weight can be analyzed by using AHP and DST. Then, multiple experts are asked to predict attributes performance of all new schemes and to express it by fuzzy number. Finally, DST is applied to group decision-making, and the optimal solution is obtained. The process is shown in Figure 1.

4.1. The Construction of Evaluation Index System. A new design plan can be evaluated by scoring. The principle of scoring is that schemes which are conducive to achieve our goals will get higher scores, and vice versa. To evaluate new

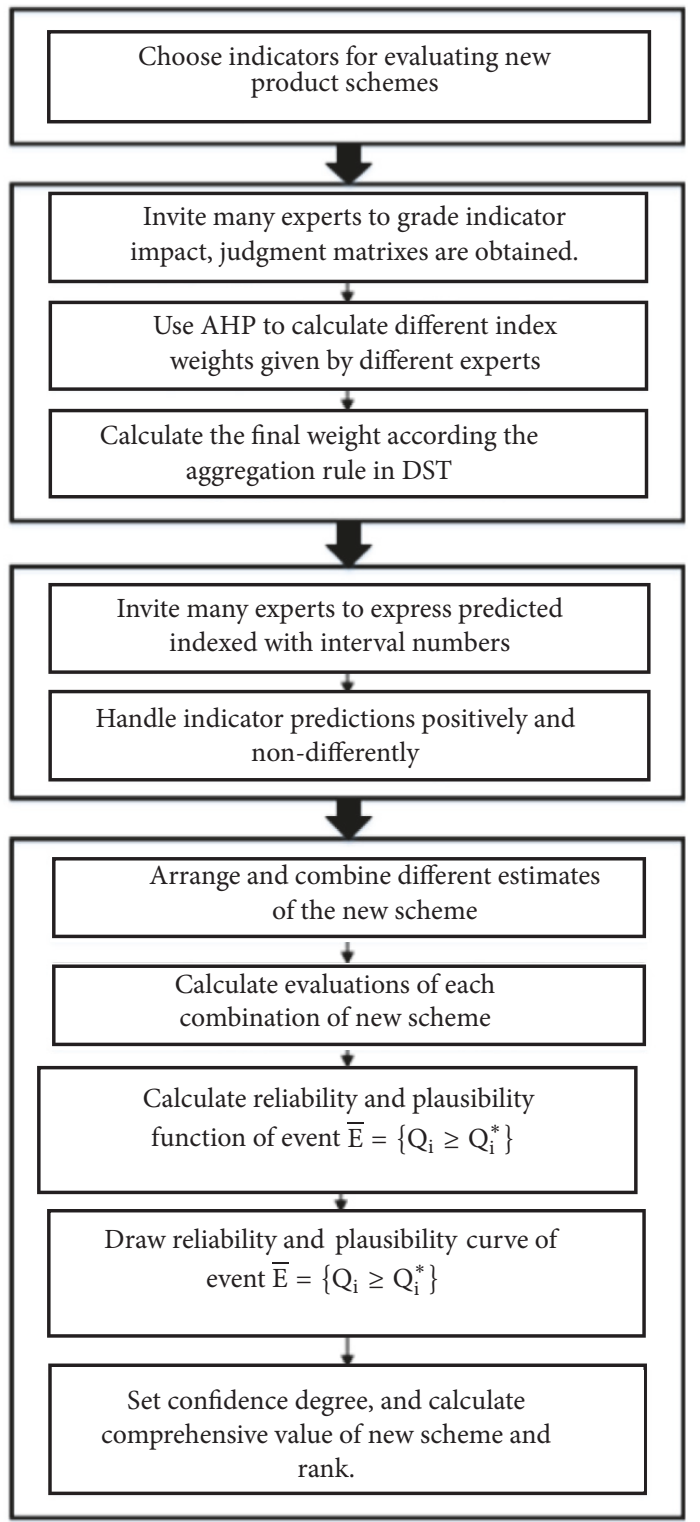

FIGURE 1: Conceptual framework of the proposed FMCGDM approach based on AHP and DST for new product selection.

product plans, goals of developing new product should be made clear firstly. Several criteria can be selected according to program purposes, and evaluation index system for new product selection is set up. Different enterprises have different goals in designing and producing new products. Enterprises design new products in order to open a new market, gain a higher market share, contribute to the environment, or obtain higher profits.

When evaluating specific product designs, indicators may vary according to previous research. For example, when a mobile phone manufacture enterprise develops a new product, indexes may be battery life, storage capacity, core processor efficiency, screen size, camera pixel, development 
TABLE 1: Scaling Method of Judgment Matrix.

\begin{tabular}{lr}
\hline Scaling value & Implication \\
\hline 1 & The two indicators are equally important \\
3 & The former indicator is slightly more important than the later. \\
7 & The former indicator is obviously more important than the later. \\
9 & The former indicator is much more important than the later. \\
$2,4,6,8$ & The former indicator is extremely more important than the later. \\
reciprocal & The median value is between two adjacent discriminates
\end{tabular}

cost, and product weight. Therefore, when selecting indicators, decision makers should modify indexes according to the goals.

\subsection{The Weights Determination Method Based on AHP and} DST. Through Section 4.1 content, indicators for new product selection have been chosen. Suppose that indexes are $\left(\begin{array}{llll}U_{1} & U_{2} & \cdots & U_{N}\end{array}\right)$. Next, we need to clarify relationship between indicators, that is, to calculate indicator weights. Weights obtained by objective methods often do not conform to the reality, and these obtained by subjective methods are influenced by expert preferences. To avoid these shortcomings, a combination of subjective and objective methods is used to calculate index weights. This method is to invite many experts to evaluate indicators importance and use AHP to calculate indicator weights. Because weights given by various experts are different, so in this paper, DST is used to calculate the final weights.

4.2.1. The Judgment Matrix Given by Experts. Firstly, many experts are invited to grade the impact of all indicators on the target. Experts can give evaluating information on the importance of the indicators according to their own professional knowledge and experience. This evaluating information can be converted into scores by comparing two indicators, as shown in Table 1.

According to this method, judgment matrix on the importance of indexes given by all experts can be obtained. Then judgment matrix given by the $\mathrm{m}$-th expert is represented by $\mathrm{A}^{\mathrm{m}}$ :

$$
\mathrm{A}^{\mathrm{m}}=\left[\left(\begin{array}{ccc}
\mathrm{a}_{11}^{\mathrm{m}} & \cdots & \mathrm{a}_{1 \mathrm{n}}^{\mathrm{m}} \\
\vdots & \ddots & \vdots \\
\mathrm{a}_{\mathrm{n} 1}^{\mathrm{m}} & \cdots & \mathrm{a}_{\mathrm{nn}}^{\mathrm{m}}
\end{array}\right)\right]
$$

4.2.2. Weight-Making by AHP. In order to estimate the impact of all indexes on the design selection, AHP [41] is used to calculate index weights. The calculation process is as follows.

Normalization. In order to calculate eigenvalues, judgment matrix given by every expert is normalized firstly. According to formula (10), judgment matrix is normalized and the normalized matrix $A_{i j}^{m^{\prime}}$ is obtained. According to formula (11), the normalized matrix is summed by rows:

$$
\begin{aligned}
\mathrm{a}_{\mathrm{ij}}^{\mathrm{m}^{\prime}} & =\frac{\mathrm{a}_{\mathrm{ij}}^{\mathrm{m}}}{\sum_{\mathrm{i}=1}^{\mathrm{n}} \mathrm{a}_{\mathrm{ij}}^{\mathrm{m}}} \\
\overline{\mathrm{W}^{\mathrm{m}}} & =\left(\overline{\omega_{1}^{\mathrm{m}}} \overline{\omega_{2}^{\mathrm{m}}} \ldots \overline{\omega_{\mathrm{n}}^{\mathrm{m}}}\right) \\
& =\left(\sum_{j=1}^{\mathrm{n}} \mathrm{a}_{1 j}^{\mathrm{m}^{\prime}} \sum_{j=1}^{\mathrm{n}} \mathrm{a}_{2 j}^{\mathrm{m}^{\prime}} \cdots \sum_{\mathrm{j}=1}^{\mathrm{n}} \mathrm{a}_{\mathrm{nj}}^{\mathrm{m}^{\prime}}\right)
\end{aligned}
$$

Eigenvalues and Maximum Eigenvectors of Judgment Matrix. According to formula (12), eigenvectors are calculated, and indicator weights given by the m-th expert are obtained. According to formula (13), the maximum eigenvalue is calculated:

$$
\begin{aligned}
\mathrm{W}^{\mathrm{m}} & =\left(\omega_{1}^{\mathrm{m}} \omega_{2}^{\mathrm{m}} \cdots \omega_{\mathrm{n}}^{\mathrm{m}}\right) \\
& =\left(\frac{\overline{\omega_{1}^{\mathrm{m}}}}{\sum_{\mathrm{i}=1}^{\mathrm{n}} \overline{\omega_{\mathrm{i}}^{\mathrm{m}}}} \frac{\overline{\omega_{2}^{\mathrm{m}}}}{\sum_{\mathrm{i}=1}^{\mathrm{n}} \overline{\omega_{\mathrm{i}}^{\mathrm{m}}}} \cdots \frac{\overline{\omega_{\mathrm{n}}^{\mathrm{m}}}}{\sum_{\mathrm{i}=1}^{\mathrm{n}} \overline{\omega_{\mathrm{i}}^{\mathrm{m}}}}\right) \\
\lambda_{\max }^{\mathrm{m}} & =\sum_{\mathrm{i}=1}^{\mathrm{n}} \frac{\left(\mathrm{AW}^{\mathrm{m}}\right)_{\mathrm{i}}}{\mathrm{n} \omega_{\mathrm{i}}^{\mathrm{m}}}
\end{aligned}
$$

Consistency Test. Consistency test is to judge the credibility of experts' scores:

$$
\mathrm{CR}=\frac{\mathrm{CI}}{\mathrm{RI}}
$$

where $\mathrm{CR}$ is the consistency test ratio, $\mathrm{RI}$ is a random consistency index, as shown in Table 2, and CI is consistency coefficient of judgment matrix, and it can be calculated as

$$
\mathrm{CI}=\frac{\lambda_{\max }-\mathrm{n}}{\mathrm{n}-1}
$$

According to formula (14), the value of CR can be calculated. If $\mathrm{CR}<0.1$ is true, the inconsistency degree is within the acceptable range. The weights given by this expert are considered to be valid. Conversely, the inconsistency degree is unacceptable. 
TABLE 2: The table of Random Consistency Indicators RI.

\begin{tabular}{llllcccccccc}
\hline $\mathrm{n}$ & 1 & 2 & 3 & 4 & 5 & 6 & 7 & 8 & 9 & 10 & 11 \\
\hline $\mathrm{RI}$ & 0 & 0 & 0.58 & 0.9 & 1.12 & 1.24 & 1.32 & 1.41 & 1.45 & 1.49 & 1.51 \\
\hline
\end{tabular}

TABLE 3: Index weight given by different expert.

\begin{tabular}{lccc}
\hline Expert & Index A & Index B & Index C \\
\hline Expert 1 & 0.4 & 0.3 & 0.3 \\
Expert 2 & 0.3 & 0.35 & 0.35 \\
\hline
\end{tabular}

4.2.3. The Final Weight Determination Based on DST. In Section 4.2.2, index weights can be calculated by using judgment matrixes given by all experts. If the weights given by different experts are the same with each other, index weights can be obtained. However, judgment matrix given by different experts is often various due to their respective knowledge and experiences. So these weights calculated by judgment matrixes given by different experts are different. DST is used to synthetically analyze different weights of the same index given by different experts and calculate the final index weights. The aggregation rule of multiple independent information sources in DST can be used to solve this problem.

For example, three indicator weights given by two experts are calculated through AHP method. The calculation results are shown in Table 3.

Using aggregation rule in DST, the calculation process of the final index weights is as follows:

$$
\begin{array}{r}
\mathrm{K}=1-\mathrm{m}_{1}(\mathrm{~A}) * \mathrm{~m}_{2}(\mathrm{~B})+\mathrm{m}_{1}(\mathrm{~A}) * \mathrm{~m}_{2}(\mathrm{C})+\mathrm{m}_{1}(\mathrm{~B}) \\
\quad * \mathrm{~m}_{2}(\mathrm{~A})+\mathrm{m}_{1}(\mathrm{~B}) * \mathrm{~m}_{2}(\mathrm{C})+\mathrm{m}_{1}(\mathrm{C}) * \mathrm{~m}_{2}(\mathrm{~A}) \\
\quad+\mathrm{m}_{1}(\mathrm{C}) * \mathrm{~m}_{2}(\mathrm{~B})=1-(0.4 * 0.35+0.4 * 0.35 \\
\quad+0.3 * 0.3+0.3 * 0.35+0.3 * 0.3+0.3 * 0.35) \\
\quad=0.33 \\
\operatorname{Bel}(\mathrm{A})=\mathrm{m}_{1}(\mathrm{~A}) * \frac{\mathrm{m}_{2}(\mathrm{~A})}{\mathrm{K}}=0.4 * \frac{0.3}{0.33}=0.3636 \\
\operatorname{Bel}(\mathrm{B})=\mathrm{m}_{1}(\mathrm{~B}) * \frac{\mathrm{m}_{2}(\mathrm{~B})}{\mathrm{K}}=0.3 * \frac{0.35}{0.33}=0.3182 \\
\operatorname{Bel}(\mathrm{C})=\mathrm{m}_{1}(\mathrm{C}) * \frac{\mathrm{m}_{2}(\mathrm{C})}{\mathrm{K}}=0.3 * \frac{0.35}{0.33}=0.3182
\end{array}
$$

4.3. The Indicator Prediction Represented by Interval Number. Multiple experts are invited to estimate the future performance of all indicators of new product schemes. Because it is a prediction for future, experts use fuzzy number more confidently compared to using numerical values to assess the possible future performance of every scheme.

For different indicators, date dimension is different. So it needs to be put in the same dimension so as to avoid mistake in the final results. Index system to evaluate new schemes includes positive index and negative index. In order to facilitate calculation, the negative data needs to be put forward. So there are two main steps in data processing, namely, nondimensional process and positive management.

4.3.1. Nondimensional Process. The indicators are represented by values or interval numbers. In this paper, min-max is mainly used to nondimensionalize.

For numerical data, the nondimensional formula (17) is as follows:

$$
x_{i j}^{\prime}=\frac{x_{i j}-x_{\min , j}}{x_{\max , j}-x_{\min , j}}
$$

where $x_{i j}$ represents the value of the $j$ th index of the ith scheme and $\mathrm{x}_{\mathrm{ij}}^{\prime}$ represents the nondimensional data of the $\mathrm{jth}$ index of the ith scheme. $x_{\max , j}$ and $x_{\min , j}$ are used to represent the maximum and minimum values of the $j$ th index data, respectively. $\mathrm{i}=1,2, \cdots, \mathrm{M}$ and $\mathrm{j}=1,2, \cdots, \mathrm{N}$. M is the total number of programs, and $\mathrm{N}$ is the total number of indicators.

For interval numbers, the nondimensional formula is as follows:

$$
\begin{aligned}
& a_{\mathrm{ij}}^{-\prime}=\frac{\mathrm{a}_{\mathrm{ij}}^{-}-\min _{0 \leq \mathrm{k} \leq \mathrm{m}}\left\{\mathrm{a}_{\mathrm{kj}}^{-}\right\}}{\max _{0 \leq \mathrm{k} \leq \mathrm{m}}\left\{\mathrm{a}_{\mathrm{kj}}^{+}\right\}-\min _{0 \leq \mathrm{k} \leq \mathrm{m}}\left\{\mathrm{a}_{\mathrm{kj}}^{-}\right\}} \\
& \mathrm{a}_{\mathrm{ij}}^{+\prime}=\frac{\mathrm{a}_{\mathrm{ij}}^{+}-\min _{0 \leq \mathrm{k} \leq \mathrm{m}}\left\{\mathrm{a}_{\mathrm{kj}}^{-}\right\}}{\max _{0 \leq \mathrm{k} \leq \mathrm{m}}\left\{\mathrm{a}_{\mathrm{kj}}^{+}\right\}-\min _{0 \leq \mathrm{k} \leq \mathrm{m}}\left\{\mathrm{a}_{\mathrm{kj}}^{-}\right\}}
\end{aligned}
$$

where $\left[a_{i j}^{-}, a_{i j}^{+}\right]$represents the value of the jth index of the ith scheme, and $\left[a_{i j}^{-\prime}, a_{i j}^{+\prime}\right]$ is used to represent the nondimensional data of the $\mathrm{jth}$ index of the ith scheme. $\min _{0 \leq \mathrm{k} \leq \mathrm{m}}\left\{\mathrm{a}_{\mathrm{kj}}^{-}\right\}$is the minimum lower limit value of the $\mathrm{jth}$ index. $\max _{0 \leq \mathrm{k} \leq \mathrm{m}}\left\{\mathrm{a}_{\mathrm{kj}}^{+}\right\}$is the maximum upper limit value of the jth index. $\mathrm{i}=1,2, \cdots, \mathrm{M}, \mathrm{j}=1,2, \cdots, \mathrm{N}$, where $\mathrm{M}$ represents the total number of programs and $\mathrm{N}$ represents the total number of indicators.

4.3.2. Positive Management. Indicators can be divided into positive and negative indicators. Positive indicators are the indicators that mean that the higher the values are, the better the schemes are. The negative indicators are the indicators that mean that the smaller the indexes are, the better the product is. In order to make calculation more convenient, negative indicators need to be transformed into positive indicators. 
For numerical data, forward processing formula is as follows:

$$
\mathrm{x}_{\mathrm{ij}}^{\prime \prime}=1-\mathrm{x}_{\mathrm{ij}}^{\prime}
$$

where $\mathrm{x}_{\mathrm{ij}}^{\prime}$ stands for the nondimensional data of the $\mathrm{jth}$ index of the ith scheme, and $x_{i j}^{\prime \prime}$ stands for the forward data of the jth index of the ith scheme

For interval number, forward processing formula is as follows:

$$
\begin{aligned}
& a_{i j}^{+\prime \prime}=1-a_{i j}^{-\prime} \\
& a_{i j}^{-\prime \prime}=1-a_{i j}^{+\prime}
\end{aligned}
$$

where $\left[a_{i j}^{-\prime}, a_{i j}^{+\prime}\right]$ stands for the nondimensional data of the $j$ th index of the ith scheme, and $\left[a_{i j}^{-\prime \prime}, a_{i j}^{+\prime \prime}\right]$ stands for the forward data of the jth index of the ith scheme.

4.4. Evaluation of New Product Scheme Based on DST. It is difficult for experts to predict future data accurately, especially on accurate number. Therefore, experts use interval numbers more confidently to predict future data based on their experience and knowledge. What is more, in order to avoid the preference of individual expert and improve the accuracy of prediction, several experts were invited to predict the indicators. The assumption that these experts are equally familiar with new products is made. This means that every expert has the same credibility. In other words, indicator values proposed by every expert appear with the same probability. For example, n experts are asked to estimate the $j$-th index of the $i$-th scheme and $n$ estimates are obtained. Then, the probability of every estimate is $1 / \mathrm{n}$.

All experts should estimate all indicators of all new schemes. Let interval number $\mathrm{a}_{\mathrm{ijm}}$ characterize the estimated value given by the $m$-th expert to the $j$-th index attribute of the i-th scheme. In order to take into account all possible future values of new scheme, different estimates would be arranged and combined. If there are $\mathrm{P}$ experts and $\mathrm{Q}$ indicators, there will be $\mathrm{P}^{\mathrm{Q}}$ possible combinations for every scheme. Only through analyzing comprehensively these combinations can evaluation results of new schemes be obtained.

For clarity, suppose there are three indicators and two experts. The two experts predicted all indicators of a new scheme, and the results are shown in Table 4. All possible combinations of the new scheme are as shown in Table 5. The number of combinations is $2^{3}=8$. The probability of occurrence of every combination is equal; all are 1/8.

Next, comprehensive evaluation of all combination can be calculated, which is equal to multiplying the attributes and the corresponding weights and then accumulating them. The calculation process of the comprehensive value of the r-th combination of the i-th new scheme is as follows:

$$
\begin{aligned}
& \mathrm{Q}_{\mathrm{ir}}=\mathrm{AW}=\left[\begin{array}{llll}
\mathrm{a}_{\mathrm{ir} 1} & \mathrm{a}_{\mathrm{ir} 2} & \cdots & \mathrm{a}_{\mathrm{irn}}
\end{array}\right] *\left[\begin{array}{llll}
\mathrm{w}_{1} & \mathrm{w}_{2} & \cdots & \mathrm{w}_{\mathrm{n}}
\end{array}\right]^{\mathrm{T}} \\
& =\sum_{j=1}^{n} a_{i r j} * w_{j}=\left[\sum_{j=1}^{n} a_{i r j}^{-} * w_{j}, \sum_{j=1}^{n} a_{i r j}^{+} * w_{j}\right]
\end{aligned}
$$

A project would have $\mathrm{P}^{\mathrm{Q}}$ comprehensive evaluations, and they are interval numbers. This makes sorting all new schemes difficult. A numerical value $Q_{i}^{*}$ which represented the final evaluation of the $\mathrm{i}$-th scheme is needed. In order to synthesize the available information and make them useful for new product selection, let us consider event $\bar{E}=\left\{Q_{i} \geq\right.$ $\mathrm{Q}_{i}^{*}$, where the evaluation of the $\mathrm{i}$-th new product, i.e. $\mathrm{Q}_{\mathrm{i}}$, is compared with a generic threshold value $Q_{i}^{*}$. To reckon $Q_{i}^{*}$ by this method is calculated from a conservative point of view. If event $\bar{E}=\left\{Q_{i} \geq Q_{i}^{*}\right\}$ occurs, the actual evaluation of new scheme is more than $Q_{i}^{*}$. If the evaluation of new scheme $\mathrm{Q}_{\mathrm{i}}^{*}$ is acceptable, the probability that the actual evaluation of the new scheme is greater than $\mathrm{Q}_{\mathrm{i}}^{*}$ is very large. So the new scheme must be acceptable. The probability of occurrence of event $\bar{E}=\left\{Q_{i} \geq Q_{i}^{*}\right\}$ should be calculated though Dempster aggregation rules. The greater the probability of evidence support is, the more likely the event is to occur. Because it is difficult to calculate the probability of event $\bar{E}=\left\{Q_{i} \geq Q_{i}^{*}\right\}$ directly, the confidence interval of inverse event $\mathrm{E}$ can be calculated firstly. By definition, $[\mathrm{Bel}(\mathrm{E}), \mathrm{Pl}(\mathrm{E})]$ stands for the trust interval of event E. Bel (E) denotes the lower limit, and $\mathrm{Pl}(\mathrm{E})$ denotes the upper limit.

(i) The reliability function of event E can be calculated according to

$$
\operatorname{Bel}(\mathrm{E})=\operatorname{Bel}\left(\mathrm{Q}_{\mathrm{i}} \leq \mathrm{Q}_{\mathrm{i}}^{*}\right)=\sum_{\mathrm{Q}_{\mathrm{i}} \in\left[0, \mathrm{Q}_{\mathrm{i}}^{*}\right]} \mathrm{m}\left(\mathrm{Q}_{\mathrm{ir}}\right)
$$

(ii) The plausibility function of event E can be calculated according to

$$
\operatorname{Pl}(\mathrm{E})=\operatorname{Pl}\left(\mathrm{Q}_{\mathrm{i}} \leq \mathrm{Q}_{\mathrm{i}}^{*}\right)=\sum_{\mathrm{Q}_{\mathrm{i}} \cap\left[0, \mathrm{Q}_{\mathrm{i}}^{*}\right]=\emptyset} \mathrm{m}\left(\mathrm{Q}_{\mathrm{ir}}\right)
$$

(iii) The reliability function and plausibility function of inverse event $\overline{\mathrm{E}}$ can be obtained by calculating the reliability function and plausibility function of event E according to

$$
\begin{gathered}
\operatorname{Bel}(\overline{\mathrm{E}})=\operatorname{Bel}\left(\mathrm{Q}_{\mathrm{i}} \geq \mathrm{Q}_{\mathrm{i}}^{*}\right)=1-\operatorname{Pl}\left(\mathrm{Q}_{\mathrm{i}} \leq \mathrm{Q}_{\mathrm{i}}^{*}\right) \\
\operatorname{Pl}(\overline{\mathrm{E}})=\operatorname{Pl}\left(\mathrm{Q}_{\mathrm{i}} \geq \mathrm{Q}_{\mathrm{i}}^{*}\right)=1-\operatorname{Bel}\left(\mathrm{Q}_{\mathrm{i}} \leq \mathrm{Q}_{\mathrm{i}}^{*}\right)
\end{gathered}
$$

It is more reasonable to determine the $Q_{i}^{*}$ from the curve depicted by the last equation, since the greater the comprehensive evaluation is, the better the scheme is. Set a confidence degree $\mathrm{g}$. As long as plausibility function of inverse event $\bar{E}=\left\{Q_{i} \geq Q_{i}^{*}\right\}$ is greater than the confidence degree $g$, the value of $Q_{i}^{*}$ is reasonable. The value of $Q_{i}^{*}$ is the abscissa of the intersection point of line $y=g$ (parallel to $x-$ axis) and plausibility function curve. In this way, $Q_{i}^{*}$ can be used to rank the new schemes to get the optimal one.

Here, there is still a problem; that is, the $Q_{i}^{*}$ of more than one schemes obtained by plausibility function may be equal. In order to rank the schemes with same $\mathrm{Q}_{\mathrm{i}}^{*}$, reliability value $r$ of event $\bar{E}=\left\{Q_{i} \geq Q_{i}^{*}\right\}$ is solved for sorting. The $r$ is the longitudinal coordinate of the intersection point of line $\mathrm{x}=$ 
TABle 4: Experts' Predictions to Indicators.

\begin{tabular}{lccc}
\hline Expert & Indicator 1 & Indicator 2 & Indicator 3 \\
\hline Expert A & {$[0.5,0.6]$} & {$[0.3,0.4]$} & {$[0.9,1]$} \\
Expert B & {$[0.3,0.4]$} & {$[0.2,0.3]$} & {$[0.8,0.9]$} \\
\hline
\end{tabular}

TABLE 5: All possible combinations.

\begin{tabular}{lccc}
\hline combination & Indicator 1 & Indicator 2 & Indicator 3 \\
\hline 1 & {$[0.5,0.6]$} & {$[0.3,0.4]$} & {$[0.9,1]$} \\
2 & {$[0.5,0.6]$} & {$[0.3,0.4]$} & {$[0.8,0.9]$} \\
3 & {$[0.5,0.6]$} & {$[0.2,0.3]$} & {$[0.9,1]$} \\
4 & {$[0.5,0.6]$} & {$[0.2,0.3]$} & {$[0.8,0.9]$} \\
5 & {$[0.3,0.4]$} & {$[0.3,0.4]$} & {$[0.9,1]$} \\
6 & {$[0.3,0.4]$} & {$[0.3,0.4]$} & {$[0.8,0.9]$} \\
7 & {$[0.3,0.4]$} & {$[0.2,0.3]$} & {$[0.9,1]$} \\
8 & {$[0.3,0.4]$} & {$[0.2,0.3]$} & {$[0.8,0.9]$} \\
\hline
\end{tabular}

$\mathrm{Q}_{\mathrm{i}}^{*}$ and reliability function curve. If the $\mathrm{r}$ is equal, change confidence degree $g$ and then solve $Q_{i}^{*}$. Repeat the above steps until a comparison can be made.

The calculation process is as follows.

(i) Set a confidence level g. Draw a line $y=g$ parallel to the $\mathrm{X}$ axis, and the intersection point of this line and plausibility function curve is $\left(\mathrm{Q}_{\mathrm{i}}^{*} \mathrm{~g}\right)$, so as to obtain $\mathrm{Q}_{\mathrm{i}}^{*}$.

(ii) By comparing $\mathrm{Q}_{\mathrm{i}}^{*}$, new schemes are sorted.

(iii) If there are no two or more schemes with equal $\mathrm{Q}_{i}^{*}$, the calculation process is over.

(iv) If there is more than one scheme with equalQ $Q_{i}^{*}$, the reliability value $r$ of event $\bar{E}=\left\{Q_{i} \geq Q_{i}^{*}\right\}$ should be calculated. Draw a line $\mathrm{x}=\mathrm{Q}_{\mathrm{i}}^{*}$ parallel to $\mathrm{Y}$ axis, and the intersection point of this line and reliability function curve is $\left(Q_{i}^{*}, r\right)$. By this way, the $r$ can be obtained.

(v) By comparing $r$, scheme with equal $\mathrm{Q}_{\mathrm{i}}^{*}$ are sorted.

(vi) If the reliability value $r$ of new schemes with equal $Q_{i}^{*}$ are not equal, the calculation process is over.

(vii) If there are more than one scheme with equal $\mathrm{Q}_{\mathrm{i}}^{*}$ and $r$, a new confidence level $g^{\prime}$ is set to rank schemes with equal $r$ and $Q_{i}^{*}$, and $g^{\prime} \neq \mathrm{g}$. Repeat steps (i)-(v) until all schemes are sorted completely. The calculation process can be shown in Figure 2.

\section{Case Study}

In order to prove the application of this method in new product selection, a case study of a household appliances manufacturing enterprise would be introduced in this section. This household appliances manufacturer is located in Qingdao, China. Regarding product innovation and user's needs as key factors for its development, this company has invested a lot of money in product development and market research. This also enables this enterprise to obtain many new product schemes. How to choose the right products is an important problem. The names and technical characteristics of new schemes are not provided in this study, since these are confidential contents to this corporation. The name of new schemes is replaced by Arabic numerals, and estimations are given by experts directly without discussing the feature information.

5.1. Decision Attributes for NPD. The goal of choosing new products to this enterprise is for the better development. How to select appropriate attributes from many factors which affect enterprise growth is the first problem to be solved. The correctness of enterprise decision-making is influenced by the quality and quantity of attributes. In order to construct appropriate indicator system, the company leaders invited several departmental representatives to set up a new product committee. These departmental representatives are from marketing, finance, $\mathrm{R} \& \mathrm{D}$, and product department. Through analyzing and screening all factors, the five indicators are selected in the final, namely, Technical Difficulty $\left(\mathrm{C}_{1}\right)$, Product Performance $\left(\mathrm{C}_{2}\right)$, Market Potential $\left(\mathrm{C}_{3}\right)$, Project Risk $\left(\mathrm{C}_{4}\right)$, and Project Cost $\left(\mathrm{C}_{5}\right)$. Technical Difficulty $\left(\mathrm{C}_{1}\right)$ is product complexities which highlight physical possibility of product realization. Product Performance $\left(\mathrm{C}_{2}\right)$ is superior quality and new product features. Market Potential $\left(\mathrm{C}_{3}\right)$ reflects the market demand. Project Risk $\left(\mathrm{C}_{4}\right)$ is about all things that might prevent successful completion. Project Cost $\left(\mathrm{C}_{5}\right)$ depicts the consumption of resources. The specific contents of the indicators are shown in Table 6.

5.2. A Weight Determination Method Based on AHP and DST for NPD. The indicators for evaluating new product schemes are selected though Section 5.1, and the next important thing is to determine these indicator weights. In this paper, four experts involved from different departments in the company 


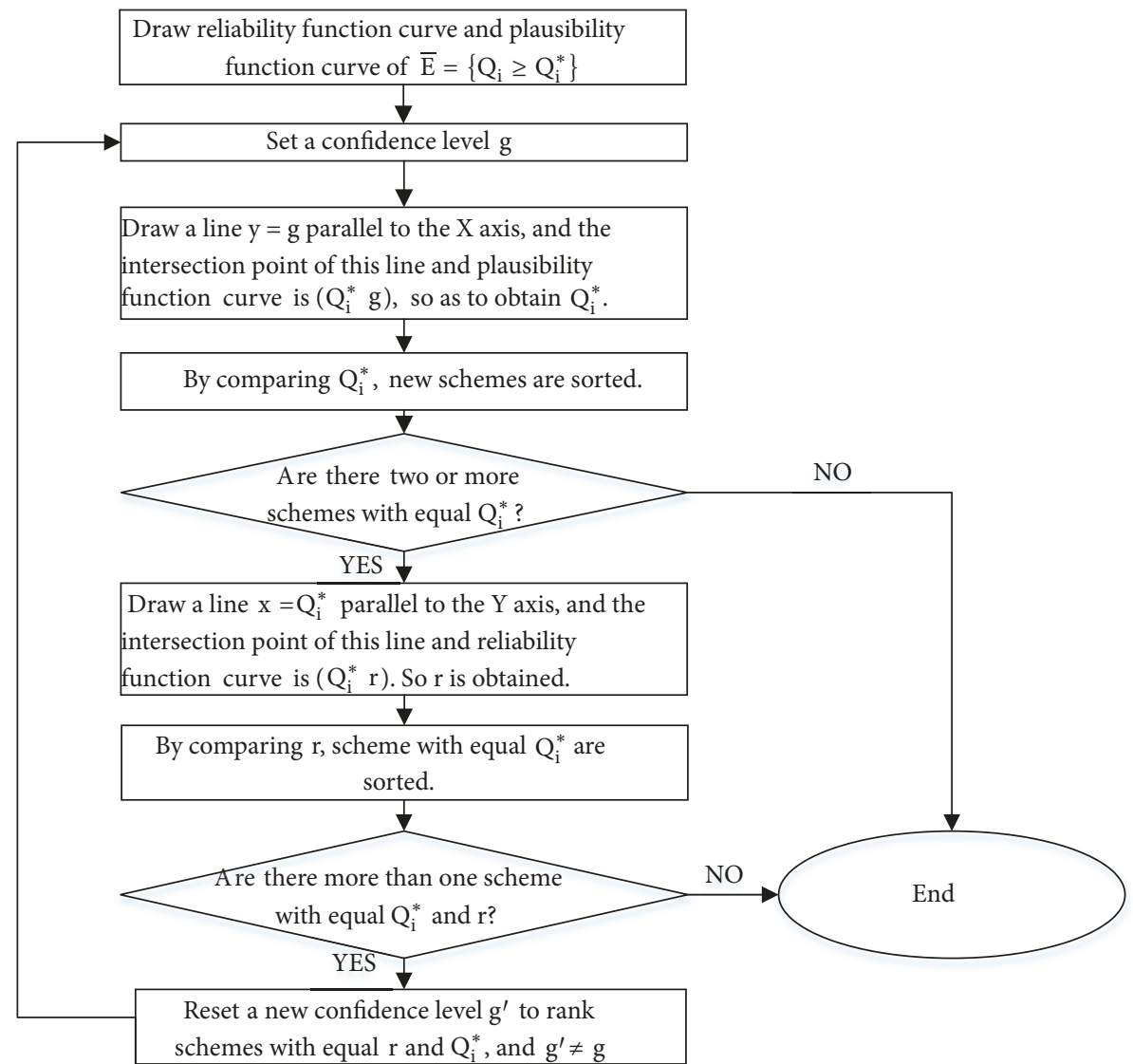

FIGURE 2: Flow diagram of the prioritization procedure for new product selection.

were invited to score the importance of the indicators. They are from marketing, finance, $\mathrm{R} \& \mathrm{D}$, and product department and have been working in this company for more than five years. The four managers scored the indicator importance according to the scoring scale of Table 1. Four judgment matrices are obtained, as follows:

$$
\begin{aligned}
& \mathrm{A}^{1}=\left(\begin{array}{lllll}
1 & \frac{1}{2} & \frac{1}{3} & \frac{1}{2} & 1 \\
2 & 1 & \frac{1}{2} & 1 & 2 \\
3 & 2 & 1 & 1 & 3 \\
2 & 1 & 1 & 1 & 2 \\
1 & \frac{1}{2} & \frac{1}{3} & \frac{1}{2} & 1
\end{array}\right) \\
& \mathrm{A}^{2}=\left(\begin{array}{lllll}
1 & 3 & 1 & 3 & 2 \\
\frac{1}{3} & 1 & \frac{1}{2} & 1 & \frac{1}{2} \\
1 & 2 & 1 & 2 & 1 \\
\frac{1}{3} & 1 & \frac{1}{2} & 1 & \frac{1}{2} \\
\frac{1}{2} & 2 & 1 & 2 & 1
\end{array}\right)
\end{aligned}
$$

$$
\begin{aligned}
\mathrm{A}^{3} & =\left(\begin{array}{ccccc}
1 & \frac{1}{2} & 2 & \frac{1}{2} & 1 \\
2 & 1 & 3 & 1 & 2 \\
\frac{1}{2} & \frac{1}{3} & 1 & \frac{1}{2} & \frac{1}{2} \\
2 & 1 & 2 & 1 & 2 \\
1 & \frac{1}{2} & 2 & \frac{1}{2} & 1
\end{array}\right) \\
\mathrm{A}^{4} & =\left(\begin{array}{ccccc}
1 & \frac{1}{2} & \frac{1}{2} & \frac{1}{3} & \frac{1}{2} \\
2 & 1 & 1 & \frac{1}{2} & \frac{1}{2} \\
2 & 1 & 1 & \frac{1}{2} & \frac{1}{2} \\
3 & 2 & 2 & 1 & 1 \\
3 & 2 & 2 & 1 & 1
\end{array}\right)
\end{aligned}
$$

According to each expert's score on each index, the weight of each index is calculated through AHP as shown in Table 7. Because of various work experience and knowledge, multiple experts assigned different weights to the same indicators. In order to obtain more reliable weights, the aggregation rules in DST are used to calculate the final weight. It is mainly based 
on that the greater the evidence is, the greater the probability of events is. According to formula (6) and (8) in Section 3, the final index weights are obtained. The result of empowerment is as follows:

$$
\begin{aligned}
& \mathrm{w}_{1}=0.09 \\
& \mathrm{w}_{2}=0.17 \\
& \mathrm{w}_{3}=0.20 \\
& \mathrm{w}_{4}=0.37 \\
& \mathrm{w}_{5}=0.17
\end{aligned}
$$

5.3. Data Collection and Preprocessing for NPD. In Sections 5.1 and 5.2, the indicators and their weights for evaluating new product are determined. The next thing to do is to predict the future performance of all indicators of new schemes. Through the active efforts of all staff, ten new products are collected. Two experts who are very familiar with these new products took the initiative to participate in the estimation of all indicators. One expert $(\mathrm{A})$ is the manager of $\mathrm{R} \& \mathrm{D}$ and the other $(B)$ is the manager of marketing department. They have been working for more than five years and are very familiar with market and enterprise. They gave, respectively, a suitable score which is between 1 and 10 points for all indicators. Because it is a prediction, experts use interval numbers more confidently than using numerical values to assess the possible future performance of each indicator. The estimated values are shown in Table 8.

According to the data processing formula in Section 4.3, the estimated values are handled positively and nondifferently. And the results are shown in Table 9.

5.4. Evaluation and Ranking of New Product Schemes Based on DST. In Section 5.3, two experts estimated the future performance of all indicators of the ten new schemes. Because they are very familiar with these new products, the probability of occurrence of the indicator value given by the two experts is equal, namely, 1/2. Following the decomposition and merging approach given in Section 4.4, the five indicators given by the two experts are combined. The number of combinations is $2^{5}$, namely, 32.

Every combination would get a comprehensive evaluation according to formula (23), and the occurrence probability of every comprehensive value is $1 / 32$. According to the calculation process in Section 4.4, plausibility curve and belief curve of event $\bar{E}=\left\{Q_{i} \geq Q_{i}^{*}\right\}$ are drawn. Set confidence level $\mathrm{g}$ as 0.9 , and draw a line $\mathrm{y}=\mathrm{g}$ parallel to the $\mathrm{X}$ axis. The intersection point of this line and plausibility function curve is $\left(Q_{i}^{*} g\right)$, so as to obtain $Q_{i}^{*}$. Due to the limitation of space, it is impossible to list all the schemes. However, in order to illustrate this method, the new product scheme 2 is illustrated as an example. Table 10 shows 32 combinations of scheme 2 and their comprehensive values. Figure 3 shows the Belief and Plausibility curves of event $\overline{\mathrm{E}}=\left\{\mathrm{Q}_{2} \geq \mathrm{Q}_{2}^{*}\right\}$, and $\mathrm{Q}_{2}^{*}$ is 0.5 .

According to the same method, the evaluation results $\mathrm{Q}_{i}^{*}$ of these ten new products are obtained. The new products are

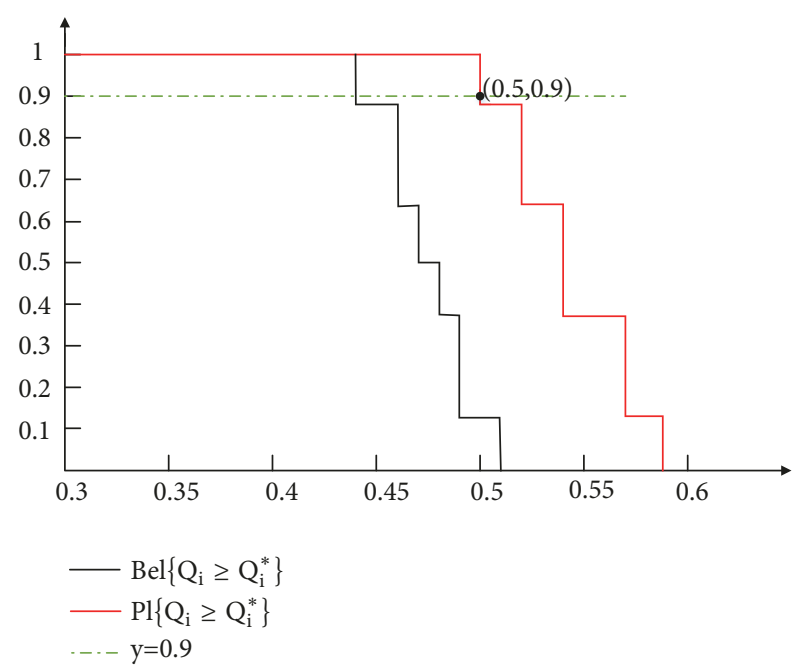

FIGURE 3: Belief and plausibility curves of new product Scheme 2.

sorted according to $\mathrm{Q}_{\mathrm{i}}^{*}$, and the ranking results are shown in Table 11.

Among them, the evaluation results $Q_{i}^{*}$ of new product schemes 4 and 5 are both 0.59 . They are equally ranked in the third position of Table 11. For the sake of clarity, the reliability value of event $\bar{E}=\left\{Q_{i} \geq 0.59\right\}$ is solved for sorting. Draw a line $\mathrm{x}=0.59$ parallel to the $\mathrm{Y}$ axis, and the intersection point of this line and reliability function curve leads to $\operatorname{Bel}\left(\mathrm{Q}_{4} \geq\right.$ $0.59)=0$, and $\operatorname{Bel}\left(Q_{5} \geq 0.59\right)=0$. Therefore, it is still impossible to rank the two schemes. Aiming at better discriminating their actual criticality, we reset confidence level $g$ as 0.8 . And draw a line $\mathrm{y}=0.8$ parallel to the $\mathrm{X}$ axis. The intersection point of this line and plausibility function curve leads to $\mathrm{Q}_{4}^{* *}=0.61$, whereas $\mathrm{Q}_{5}^{* *}=0.59$, as shown in Figures 4 and 5. The new product scheme 4 results are more critical than scheme 5 . As a consequence, the new product scheme 4 still remains in the third position of the final ranking, whereas scheme 5 shifts to the forth. The final ranking of new product schemes is shown in Table 12. In this scheme selection, scheme 6 is the best choice.

In real life, the top manager in this enterprise finally adopted scheme 8 and scheme 3 through many seminars and repeated evaluations. After successful R\&D and putting scheme 8 and scheme 3 into the market, it is found that the actual situation is the same as the result of the evaluation in this paper. New product 8 has achieved good economic returns and new scheme 3 has achieved lower economic returns, which is the same as our final evaluation.

\section{Conclusions}

The evaluation and selection of new product schemes is a prediction and decision-making process for future problems, which has many risks and uncertainties. It is one of the key events which influences the future development of enterprises. Therefore, it is imperative to take a reliable approach to assess new products. In this paper, a new method based on AHP and DST is proposed to make the best decisions in 
TABLE 6: The specific contents of the indicators.

Indicator

The specific contents

Technical Difficulty

Technological difficulty in Research, Development and Production

Product Performance The new properties, costs and physical characteristics

Market Potential Market capacity, demand trend, profit potential, competitive ability, market competition

Project Risk

Financial risks, managerial risks, envisioning risks, design risks, and execution risks

Project Cost Financial consumption, human consumption and material consumption

TABLE 7: Weights assigned by different expert.

\begin{tabular}{lcccc}
\hline Indictor & Expert A & Expert B & Expert C & Expert D \\
\hline Technical Difficulty & 0.1103 & 0.3276 & 0.1568 & 0.0975 \\
Product Performance & 0.2097 & 0.1103 & 0.2945 & 0.1568 \\
Market Potential & 0.3276 & 0.2422 & 0.0975 & 0.1568 \\
Project Risk & 0.2422 & 0.1103 & 0.2945 & 0.2945 \\
Project Cost & 0.1103 & 0.2097 & 0.1568 & 0.2945 \\
\hline
\end{tabular}

TAble 8: Table of Experts' Prediction for New Products.

\begin{tabular}{|c|c|c|c|c|c|c|c|c|c|c|}
\hline \multirow{2}{*}{$\begin{array}{l}\text { Indictor } \\
\text { Expert }\end{array}$} & \multicolumn{2}{|c|}{$\mathrm{C}_{1}$} & \multicolumn{2}{|c|}{$\mathrm{C}_{2}$} & \multicolumn{2}{|c|}{$\mathrm{C}_{3}$} & \multicolumn{2}{|c|}{$\mathrm{C}_{4}$} & \multicolumn{2}{|c|}{$\mathrm{C}_{5}$} \\
\hline & A & B & A & $\mathrm{B}$ & A & $\mathrm{B}$ & A & $\mathrm{B}$ & A & $\mathrm{B}$ \\
\hline Scheme 1 & {$[7,8]$} & {$[6,7]$} & {$[8,9]$} & 9 & {$[7,8]$} & 8 & [89]89 & 8 & 9 & 9 \\
\hline Scheme 2 & {$[7,8]$} & {$[5,6]$} & {$[4,5]$} & 4 & {$[3,4]$} & 4 & {$[5,6]$} & 5 & {$[8,9]$} & 8 \\
\hline Scheme 3 & {$[4,5]$} & 4 & {$[1,2]$} & 2 & {$[2,3]$} & 2 & {$[3,4]$} & 3 & {$[4,5]$} & 4 \\
\hline Scheme 4 & {$[8,9]$} & {$[7,8]$} & {$[4,5]$} & {$[5,6]$} & {$[4,5]$} & 5 & {$[7,8]$} & {$[6,7]$} & 8 & {$[7,8]$} \\
\hline Scheme 5 & {$[8,9]$} & {$[8,9]$} & 7 & {$[7,8]$} & 8 & {$[7,8]$} & {$[7,8]$} & {$[7,8]$} & 4 & 5 \\
\hline Scheme 6 & {$[2,3]$} & 3 & {$[2,3]$} & {$[2,3]$} & {$[9,10]$} & 9 & {$[8,9]$} & {$[7,8]$} & 9 & {$[8,9]$} \\
\hline Scheme 7 & {$[4,5]$} & {$[5,6]$} & {$[2,3]$} & 3 & {$[4,5]$} & {$[3,4]$} & {$[5,6]$} & {$[4,5]$} & {$[4,5]$} & {$[3,4]$} \\
\hline Scheme 8 & {$[7,8]$} & {$[8,9]$} & {$[4,5]$} & {$[3,4]$} & 2 & {$[2,3]$} & {$[4,5]$} & {$[5,6]$} & {$[2,3]$} & {$[1,2]$} \\
\hline Scheme 9 & {$[2,3]$} & {$[3,4]$} & {$[4,5]$} & {$[5,6]$} & {$[4,5]$} & {$[4,5]$} & {$[2,3]$} & 2 & {$[4,5]$} & {$[5,6]$} \\
\hline Scheme 10 & {$[4,5]$} & {$[3,4]$} & 2 & {$[2,3]$} & {$[1,2]$} & {$[2,3]$} & {$[1,2]$} & 1 & {$[5,6]$} & {$[5,6]$} \\
\hline
\end{tabular}

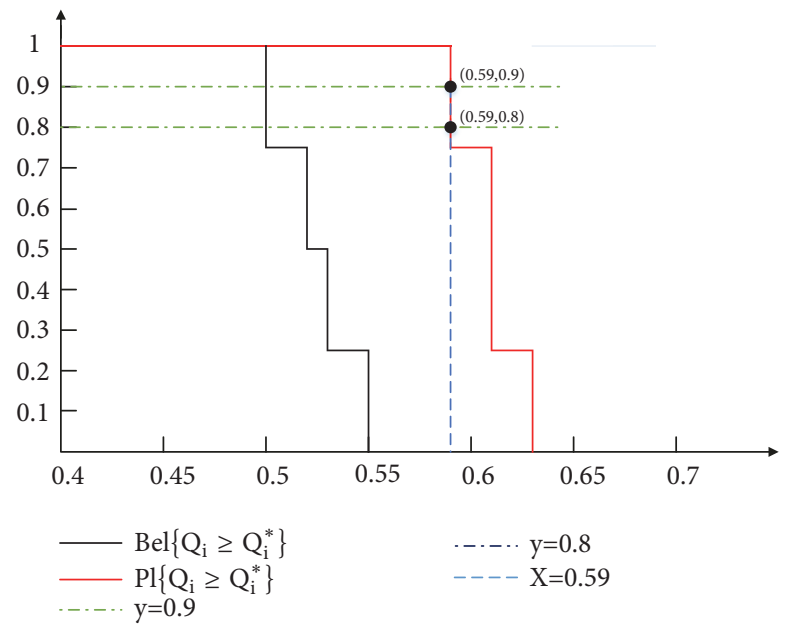

FIGURE 4: Belief and plausibility curves of new product Scheme 4.

a fuzzy environment. There are four stages in this method. The first stage is attributes selection for evaluation, which

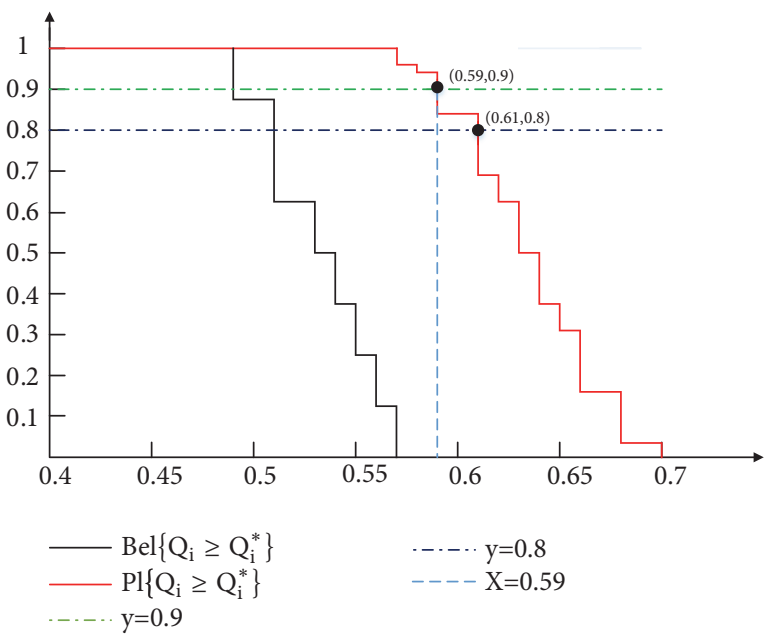

FIgURE 5: Belief and plausibility curves of new product Scheme 5. is the first stage for all decision-making problems. At this stage, we need to make clear what indicators influence new 


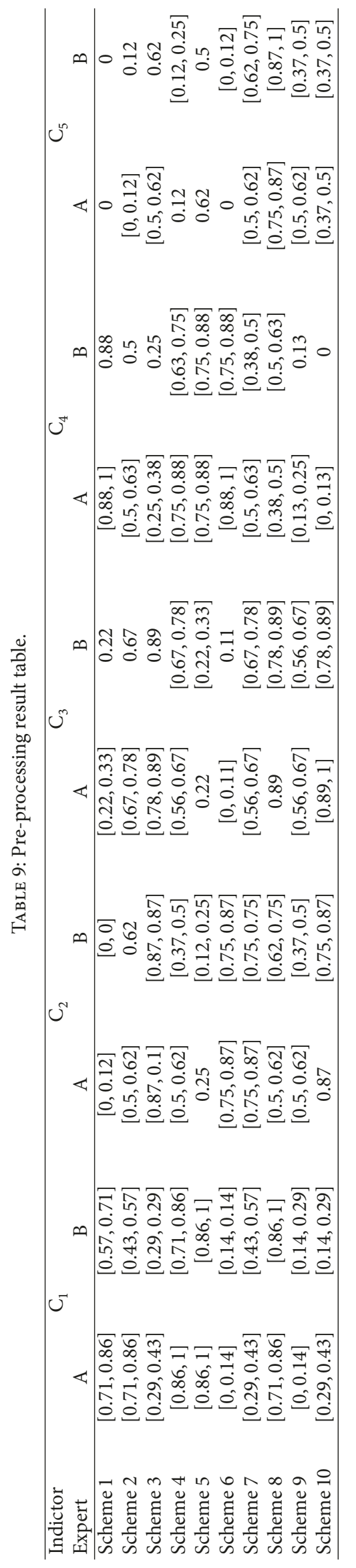


TABLE 10: The combinations of new product scheme 2.

\begin{tabular}{|c|c|c|c|c|c|c|}
\hline combination & $\mathrm{C}_{1}$ & $\mathrm{C}_{2}$ & $\mathrm{C}_{3}$ & $\mathrm{C}_{4}$ & $\mathrm{C}_{5}$ & evaluation \\
\hline 1 & {$[0.71,0.86]$} & {$[0.5,0.62]$} & {$[0.67,0.78]$} & {$[0.5,0.63]$} & {$[0,0.12]$} & {$[0.47,0.59]$} \\
\hline 2 & {$[0.71,0.86]$} & {$[0.5,0.62]$} & {$[0.67,0.78]$} & {$[0.5,0.63]$} & 0.12 & {$[0.49,0.59]$} \\
\hline 3 & {$[0.71,0.86]$} & {$[0.5,0.62]$} & {$[0.67,0.78]$} & 0.5 & {$[0,0.12]$} & {$[0.44,0.57]$} \\
\hline 4 & {$[0.71,0.86]$} & {$[0.5,0.62]$} & {$[0.67,0.78]$} & 0.5 & 0.12 & {$[0.46,0.57]$} \\
\hline 5 & {$[0.71,0.86]$} & {$[0.5,0.62]$} & 0.67 & {$[0.5,0.63]$} & {$[0,0.12]$} & {$[0.47,0.54]$} \\
\hline 6 & {$[0.71,0.86]$} & {$[0.5,0.62]$} & 0.67 & {$[0.5,0.63]$} & 0.12 & {$[0.49,0.54]$} \\
\hline 7 & {$[0.71,0.86]$} & {$[0.5,0.62]$} & 0.67 & 0.5 & {$[0,0.12]$} & {$[0.44,0.52]$} \\
\hline 8 & {$[0.71,0.86]$} & {$[0.5,0.62]$} & 0.67 & 0.5 & 0.12 & {$[0.46,0.52]$} \\
\hline 9 & {$[0.71,0.86]$} & 0.62 & {$[0.67,0.78]$} & {$[0.5,0.63]$} & {$[0,0.12]$} & {$[0.49,0.59]$} \\
\hline 10 & {$[0.71,0.86]$} & 0.62 & {$[0.67,0.78]$} & {$[0.5,0.63]$} & 0.12 & {$[0.51,0.59]$} \\
\hline 11 & {$[0.71,0.86]$} & 0.62 & {$[0.67,0.78]$} & 0.5 & {$[0,0.12]$} & {$[0.46,0.57]$} \\
\hline 12 & {$[0.71,0.86]$} & 0.62 & {$[0.67,0.78]$} & 0.5 & 0.12 & {$[0.48,0.57]$} \\
\hline 13 & {$[0.71,0.86]$} & 0.62 & 0.67 & {$[0.5,0.63]$} & {$[0,0.12]$} & {$[0.49,0.54]$} \\
\hline 14 & {$[0.71,0.86]$} & 0.62 & 0.67 & {$[0.5,0.63]$} & 0.12 & {$[0.51,0.54]$} \\
\hline 15 & {$[0.71,0.86]$} & 0.62 & 0.67 & 0.5 & {$[0,0.12]$} & {$[0.46,0.52]$} \\
\hline 16 & {$[0.71,0.86]$} & 0.62 & 0.67 & 0.5 & 0.12 & {$[0.48,0.52]$} \\
\hline 17 & {$[0.43,0.57]$} & {$[0.5,0.62]$} & {$[0.67,0.78]$} & {$[0.5,0.63]$} & {$[0,0.12]$} & {$[0.47,0.57]$} \\
\hline 18 & {$[0.43,0.57]$} & {$[0.5,0.62]$} & {$[0.67,0.78]$} & {$[0.5,0.63]$} & 0.12 & {$[0.49,0.57]$} \\
\hline 19 & {$[0.43,0.57]$} & {$[0.5,0.62]$} & {$[0.67,0.78]$} & 0.5 & {$[0,0.12]$} & {$[0.44,0.54]$} \\
\hline 20 & {$[0.43,0.57]$} & {$[0.5,0.62]$} & {$[0.67,0.78]$} & 0.5 & 0.12 & {$[0.46,0.54]$} \\
\hline 21 & {$[0.43,0.57]$} & {$[0.5,0.62]$} & 0.67 & {$[0.5,0.63]$} & {$[0,0.12]$} & {$[0.47,0.52]$} \\
\hline 22 & {$[0.43,0.57]$} & {$[0.5,0.62]$} & 0.67 & {$[0.5,0.63]$} & 0.12 & {$[0.49,0.52]$} \\
\hline 23 & {$[0.43,0.57]$} & {$[0.5,0.62]$} & 0.67 & 0.5 & {$[0,0.12]$} & {$[0.44,0.5]$} \\
\hline 24 & {$[0.43,0.57]$} & {$[0.5,0.62]$} & 0.67 & 0.5 & 0.12 & {$[0.46,0.5]$} \\
\hline 25 & {$[0.43,0.57]$} & 0.62 & {$[0.67,0.78]$} & {$[0.5,0.63]$} & {$[0,0.12]$} & {$[0.49,0.57]$} \\
\hline 26 & {$[0.43,0.57]$} & 0.62 & {$[0.67,0.78]$} & {$[0.5,0.63]$} & 0.12 & {$[0.51,0.57]$} \\
\hline 27 & {$[0.43,0.57]$} & 0.62 & {$[0.67,0.78]$} & 0.5 & {$[0,0.12]$} & {$[0.46,0.54]$} \\
\hline 28 & {$[0.43,0.57]$} & 0.62 & {$[0.67,0.78]$} & 0.5 & 0.12 & {$[0.48,0.54]$} \\
\hline 29 & {$[0.43,0.57]$} & 0.62 & 0.67 & {$[0.5,0.63]$} & {$[0,0.12]$} & {$[0.49,0.52]$} \\
\hline 30 & {$[0.43,0.57]$} & 0.62 & 0.67 & {$[0.5,0.63]$} & 0.12 & {$[0.51,0.52]$} \\
\hline 31 & {$[0.43,0.57]$} & 0.62 & 0.67 & 0.5 & {$[0,0.12]$} & {$[0.46,0.5]$} \\
\hline 32 & {$[0.43,0.57]$} & 0.62 & 0.67 & 0.5 & 0.12 & {$[0.48,0.5]$} \\
\hline
\end{tabular}

TABLE 11: New products ranking on the basis of Plausibility curves.

\begin{tabular}{lcc}
\hline Scheme & $\mathrm{Q}_{\mathrm{i}}^{*}$ & Ranking \\
\hline Scheme 1 & 0.45 & 8 \\
Scheme 2 & 0.5 & 7 \\
Scheme 3 & 0.55 & 5 \\
Scheme 4 & 0.59 & 3 \\
Scheme 5 & 0.59 & 3 \\
Scheme 6 & 0.51 & 6 \\
Scheme 7 & 0.62 & 2 \\
Scheme 8 & 0.71 & 1 \\
Scheme 9 & 0.38 & 10 \\
Scheme 10 & 0.44 & 9 \\
\hline
\end{tabular}

product selection and build an index system. The second stage is to determine the indicator weights through AHP and DST. Several experts score the indicators according to scoring criteria. Then the indicator weights given by different experts are calculated through AHP. Then the final weights are calculated through Dempster aggregation rule. In the third stage, all indexes of new schemes are predicted and preprocessed. This problem is forecasted by experts based on the fact that they are familiar with the market, enterprises, and each new scheme at the same time. Even so, experts use interval numbers more confidently to represent the indicators compared to numerical values. In order to facilitate future evaluation, we need to handle the interval values positively and nondifferently. The fourth stage is the evaluation of new schemes based on DST. By analyzing the belief and plausibility function of event $\bar{E}=\left\{Q_{i} \geq Q_{i}^{*}\right\}$, we can get the critical value $\mathrm{Q}_{i}^{*}$ with given confidence level. The critical value is used to express the evaluation of new products and to rank them. In order to prove how the proposed fuzzy hybrid method works, a new products evaluation in Qingdao is taken as an example to make an empirical study, through which the following conclusions can be drawn. 
TABLE 12: Final ranking.

\begin{tabular}{|c|c|c|c|c|}
\hline \multirow{2}{*}{ Scheme } & \multicolumn{2}{|c|}{ confidence level $\mathrm{q}=0.9$} & \multirow{2}{*}{$\begin{array}{c}\text { confidence level } \mathrm{q}=0.8 \\
\mathrm{Q}_{\mathrm{i}}^{*}\end{array}$} & \multirow{2}{*}{ Ranking } \\
\hline & $\mathrm{Q}_{\mathrm{i}}^{*}$ & $\operatorname{Pl}\left(\mathrm{Q}_{\mathrm{ir}} \geq \mathrm{Q}_{\mathrm{i}}^{*}\right)$ & & \\
\hline Scheme 8 & 0.71 & - & - & 1 \\
\hline Scheme 7 & 0.62 & - & - & 2 \\
\hline Scheme 4 & 0.59 & 0 & 0.61 & 3 \\
\hline Scheme 5 & 0.59 & 0 & 0.59 & 4 \\
\hline Scheme 3 & 0.55 & - & - & 5 \\
\hline Scheme 6 & 0.51 & - & - & 6 \\
\hline Scheme 2 & 0.5 & - & - & 7 \\
\hline Scheme 1 & 0.45 & - & - & 8 \\
\hline Scheme 10 & 0.44 & - & - & 9 \\
\hline Scheme 9 & 0.38 & - & - & 10 \\
\hline
\end{tabular}

These indicators were selected by the research team based on years of work experience. The members of the research group are middle-level managers who have more than five years' working experience in the enterprise and have a lot of practical experience of NPD. These attributes are as follows: Technical Difficulty (C1) is the product and methods complexity which highlights the physical possibility of product realization; Product Performance (C2) is the superior quality and new product features, which reflects the product substantial competitive advantage; Market Potential (C3) reflects market demand, growth, and size, which shows an increase in demand for a particular product over time; Project Risk (C4) is about any feature that might potentially interfere with successful completion, including financial risks, managerial risks, envisioning risks, design risks, and execution risks. Project Cost (C5) depicts the consumption of resources. The attributes for NPD which are put forward in this case can be used for a reference to other enterprises.

What is more, the evaluation of new products is a prediction for future problems, which has many risks and uncertainties. Because it is a prediction for future, experts use fuzzy number more confidently compared to using numerical values to assess the possible future performance of every scheme. And a number of experts are invited to predict the future performance of the new schemes, which can improve the prediction accuracy. Therefore, there would be multiple fuzzy numbers for the same index of the same scheme. This adds to the difficulty of the evaluation and ranking of new products. A new product evaluation and ranking method based on DST is proposed in this paper. Dempster-Shafer Theory (DST) is suggested as a proper mathematical framework to deal with the epistemic uncertainty. This method allows experts to use interval numbers to express indicators and obtain all possible combinations as evidence through decomposition and merging approach. Through analyzing the Belief and Plausibility curve of event $\overline{\mathrm{E}}=\left\{\mathrm{Q}_{\mathrm{ir}} \geq \mathrm{Q}_{\mathrm{i}}^{*}\right\}$, the critical value $Q_{i}^{*}$ is obtained and used as the evaluation results of the scheme and sorted.

Finally, the method based on AHP and DST proposed in this paper has higher reliability of index weights. Weight determination is a key content for MADM problem. Subjective or objective methods were used to determine weight.
However, the weight obtained by objective method often does not accord with the actual situation, and the weight obtained by subjective valuation method is often influenced by experts. The method based on DST and AHP is a comprehensive index weighting method which combines subjective and objective methods. If only one expert evaluates the importance of the index, it is difficult to ensure that the index weight is not affected by the expert's personal preferences. Therefore, many experts are often invited to evaluate the indicator weight to improve the accuracy of the evaluation. The method based on AHP and DST proposed in this paper is used to deal with the difference of index weight.

\section{Data Availability}

The data used to support the findings of this study are included within the article. No additional data are available.

\section{Conflicts of Interest}

The authors declare that they have no conflicts of interest.

\section{Acknowledgments}

This work is financially supported by National Natural Science Foundation of China under Grant No. 71771066 and 71531013 and The Key Program in the Youth Elite Support Plan in Universities of Anhui Province (GXYQZD2017084).

\section{References}

[1] K. G. Lough, R. Stone, and I. Y. Tumer, “The risk in early design method," Journal of Engineering Design, vol. 20, no. 2, pp. 155173, 2009.

[2] R. Patil, K. Grantham, and D. Steele, "Business risk in early design: a business risk assessment approach," EMJ - Engineering Management Journal, vol. 24, no. 1, pp. 35-46, 2012.

[3] C. Fang and F. Marle, "Dealing with project complexity by matrix-based propagation modelling for project risk analysis," Journal of Engineering Design, vol. 24, no. 4, pp. 239-256, 2013.

[4] M. Goswami and M. K. Tiwari, "A predictive risk evaluation framework for modular product concept selection in new 
product design environment," Journal of Engineering Design, vol. 25, no. 1-3, pp. 150-171, 2014.

[5] B. Kim and J. Kim, "Structural factors of NPD (new product development) team for manufacturability," International Journal of Project Management, vol. 27, no. 7, pp. 690-702, 2009.

[6] R. G. Cooper and E. J. Kleinschmidt, "Benchmarking the firm's critical success factors in new product development," The Journal of Product Innovation Management, vol. 12, no. 5, pp. 374-391, 1995.

[7] P.-K. Lam and K.-S. Chin, "Identifying and prioritizing critical success factors for conflict management in collaborative new product development," Industrial Marketing Management, vol. 34, no. 8, pp. 761-772, 2005.

[8] H. Ernst, "Success factors of new product development: A review of the empirical literature," International Journal of Management Reviews, vol. 4, no. 1, pp. 1-40, 2002.

[9] A. Lowe, K. Ridgway, and H. Atkinson, "QFD in new production technology evaluation," International Journal of Production Economics, vol. 67, no. 2, pp. 103-112, 2000.

[10] N. Hanumaiah, B. Ravi, and N. P. Mukherjee, "Rapid hard tooling process selection using QFD-AHP methodology," Journal of Manufacturing Technology Management, vol. 17, no. 3, pp. 332350, 2006.

[11] A. H. I. Lee and C.-Y. Lin, "An integrated fuzzy QFD framework for new product development," Flexible Services and Manufacturing Journal, vol. 23, no. 1, pp. 26-47, 2011.

[12] X. Zhang, “"User selection for collaboration in product development based on QFD and DEA approach," Journal of Intelligent Manufacturing, vol. 30, no. 5, pp. 2231-2243, 2019.

[13] L. Yu, L. Wang, and Y. Bao, "Technical attributes ratings in fuzzy QFD by integrating interval-valued intuitionistic fuzzy sets and Choquet integral," Soft Computing, vol. 22, no. 6, pp. 2015-2024, 2018.

[14] R. J. Thieme, M. Song, and R. J. Calantone, "Artificial neural network decision support systems for new product development project selection," Journal of Marketing Research, vol. 37, no. 4, pp. 499-507, 2000.

[15] Y.-C. Ho and C.-T. Tsai, "Comparing ANFIS and SEM in linear and nonlinear forecasting of new product development performance," Expert Systems with Applications, vol. 38, no. 6, pp. 6498-6507, 2011.

[16] M.-C. Lin, C.-C. Wang, M.-S. Chen, and C. A. Chang, "Using AHP and TOPSIS approaches in customer-driven product design process," Computers in Industry, vol. 59, no. 1, pp. 17-31, 2008.

[17] H. J. Shyur, "COTS evaluation using modified TOPSIS and ANP," Applied Mathematics and Computation, vol. 177, no. 1, pp. 251-259, 2006.

[18] C.-C. Chyu and Y.-C. Fang, "A hybrid fuzzy analytic network process approach to the new product development selection problem," Mathematical Problems in Engineering, vol. 2014, Article ID 485016, 13 pages, 2014.

[19] G. Akkaya, B. Turanoglu, and S. Öztaş, "An integrated fuzzy AHP and fuzzy MOORA approach to the problem of industrial engineering sector choosing," Expert Systems with Applications, vol. 42, no. 24, pp. 9565-9573, 2015.

[20] D. Joshi and S. Kumar, "Interval-valued intuitionistic hesitant fuzzy Choquet integral based TOPSIS method for multi-criteria group decision making," European Journal of Operational Research, vol. 248, no. 1, pp. 183-191, 2016.
[21] D. A. Carrera and R. V. Mayorga, "Supply chain management: a modular fuzzy inference system approach in supplier selection for new product development," Journal of Intelligent Manufacturing, vol. 19, no. 1, pp. 1-12, 2008.

[22] H. H. Chen, A. H.I. Lee, and Y. Tong, "Analysis of new product mix selection at TFT-LCD technological conglomerate network under uncertainty," Technovation, vol. 26, no. 11, pp. 1210-1221, 2006.

[23] C.-T. Lin and Y.-S. Yang, "A linguistic approach to measuring the attractiveness of new products in portfolio selection," Group Decision and Negotiation, vol. 24, no. 1, pp. 145-169, 2015.

[24] K. Y. Chan and S. H. Ling, "A forward selection based fuzzy regression for new product development that correlates engineering characteristics with consumer preferences," Journal of Intelligent \& Fuzzy Systems: Applications in Engineering and Technology, vol. 30, no. 3, pp. 1869-1880, 2016.

[25] G. Büyüközkan and S. Güleryüz, "Multi criteria group decision making approach for smart phone selection using intuitionistic fuzzy TOPSIS," International Journal of Computational Intelligence Systems, vol. 9, no. 4, pp. 709-725, 2016.

[26] K. D. Atalay and G. F. Can, "A new hybrid intuitionistic approach for new product selection," Soft Computing, vol. 22, no. 8, pp. 2633-2640, 2018.

[27] Z. Ren, Z. Xu, and H. Wang, "Dual hesitant fuzzy VIKOR method for multi-criteria group decision making based on fuzzy measure and new comparison method," Information Sciences, vol. 388-389, pp. 1-16, 2017.

[28] S. Ebrahimnejad, S. M. Mousavi, R. Tavakkoli-Moghaddam, H. Hashemi, and B. Vahdani, "A novel two-phase group decision making approach for construction project selection in a fuzzy environment," Applied Mathematical Modelling: Simulation and Computation for Engineering and Environmental Systems, vol. 36, no. 9, pp. 4197-4217, 2012.

[29] C.-C. Lo, P. Wang, and K.-M. Chao, "A fuzzy group-preferences analysis method for new-product development," Expert Systems with Applications, vol. 31, no. 4, pp. 826-834, 2006.

[30] C.-H. Yeh and Y.-H. Chang, "Modeling subjective evaluation for fuzzy group multicriteria decision making," European Journal of Operational Research, vol. 194, no. 2, pp. 464-473, 2009.

[31] G. Tuzkaya, "An intuitionistic fuzzy choquet integral operator based methodology for environmental criteria integrated supplier evaluation process," International Journal of Environmental Science and Technology, vol. 10, no. 3, pp. 423-432, 2013.

[32] G. Büyüközkan and F. Göçer, "Smart medical device selection based on intuitionistic fuzzy Choquet integral," Soft Computing, pp. 1-19, 2018.

[33] S. M. Mousavi, S. A. Torabi, and R. Tavakkoli-Moghaddam, "A hierarchical group decision-making approach for new product selection in a fuzzy environment," Arabian Journal for Science and Engineering, vol. 38, no. 11, pp. 3233-3248, 2013.

[34] I. Sarı and C. Kahraman, "New product selection using fuzzy linear programming and fuzzy montecarlo simulation," Communications in Computer \& Information Science, vol. 300, no. 3, pp. 441-448, 2012.

[35] H.-Z. Huang, Y. Liu, Y. Li, L. Xue, and Z. Wang, "New evaluation methods for conceptual design selection using computational intelligence techniques," Journal of Mechanical Science and Technology, vol. 27, no. 3, pp. 733-746, 2013.

[36] W.-P. Wang, "Evaluating new product development performance by fuzzy linguistic computing," Expert Systems with Applications, vol. 36, no. 6, pp. 9759-9766, 2009. 
[37] G. Büyüközkan and O. Feyziog̃lu, "A fuzzy-logic-based decision-making approach for new product development," International Journal of Production Economics, vol. 90, no. 1, pp. 27-45, 2004.

[38] A. Certa, M. Enea, G. M. Galante, and C. M. La Fata, "A multistep methodology for the evaluation of human resources using the evidence theory," International Journal of Intelligent Systems, vol. 28, no. 11, pp. 1072-1088, 2013.

[39] G. Shafer, "Dempster's rule of combination," International Journal of Approximate Reasoning, vol. 79, pp. 26-40, 2016.

[40] D. Li, H. Tang, S. Xue, and Y. Su, "Adaptive sub-interval perturbation-based computational strategy for epistemic uncertainty in structural dynamics with evidence theory," Probabilistic Engineering Mechanics, vol. 53, pp. 75-86, 2018.

[41] C.-H. Goh, Y.-C. A. Tung, and C.-H. Cheng, "A revised weighted sum decision model for robot selection," Computers \& Industrial Engineering, vol. 30, no. 2, pp. 193-199, 1996. 


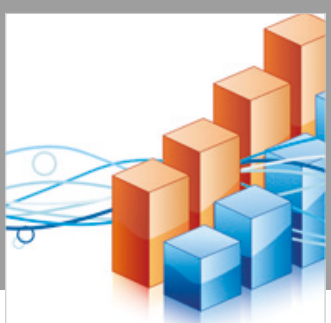

Advances in

Operations Research

\section{-n-m}
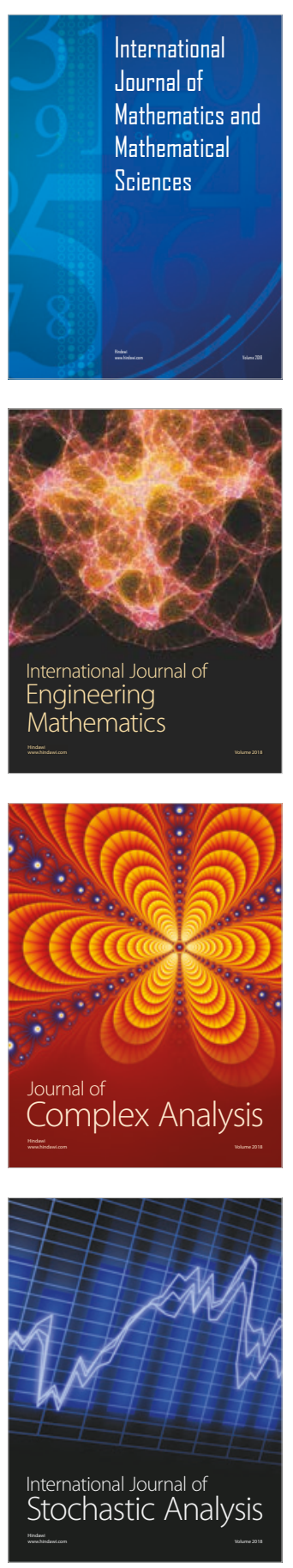
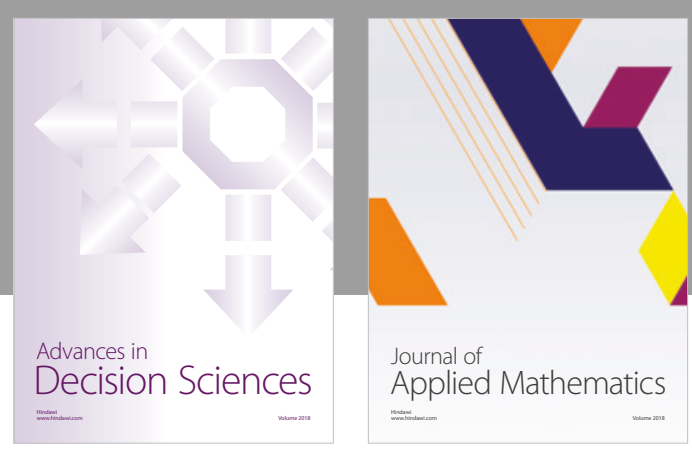

Journal of

Applied Mathematics
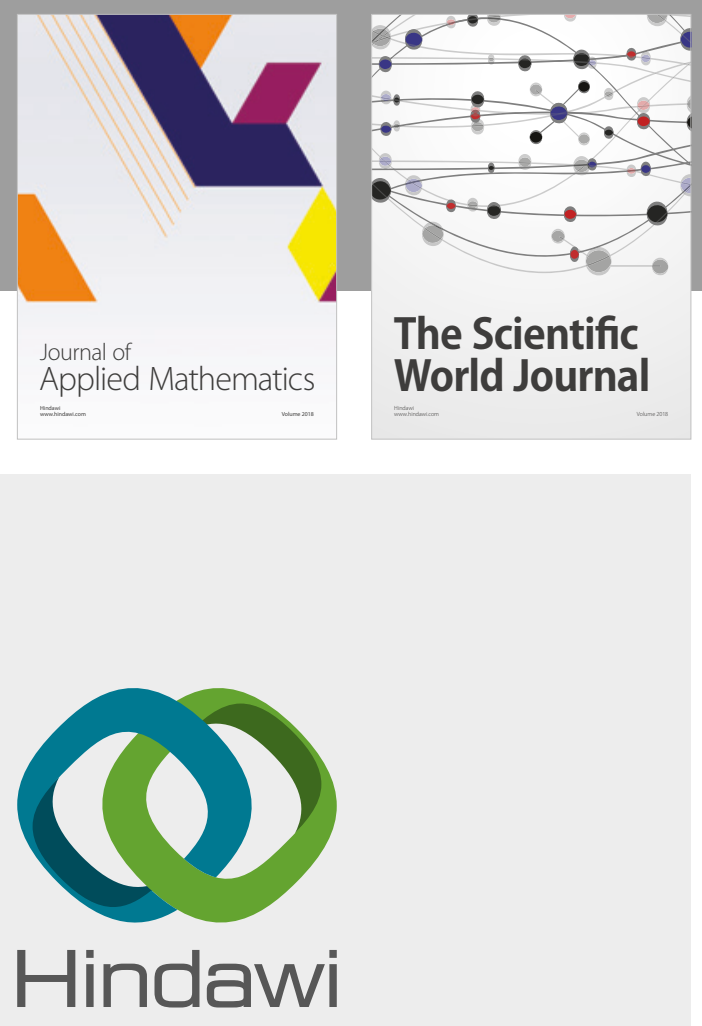

Submit your manuscripts at

www.hindawi.com

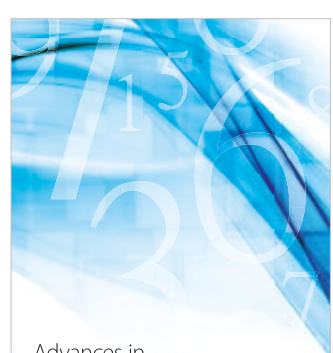

Advances in
Numerical Analysis
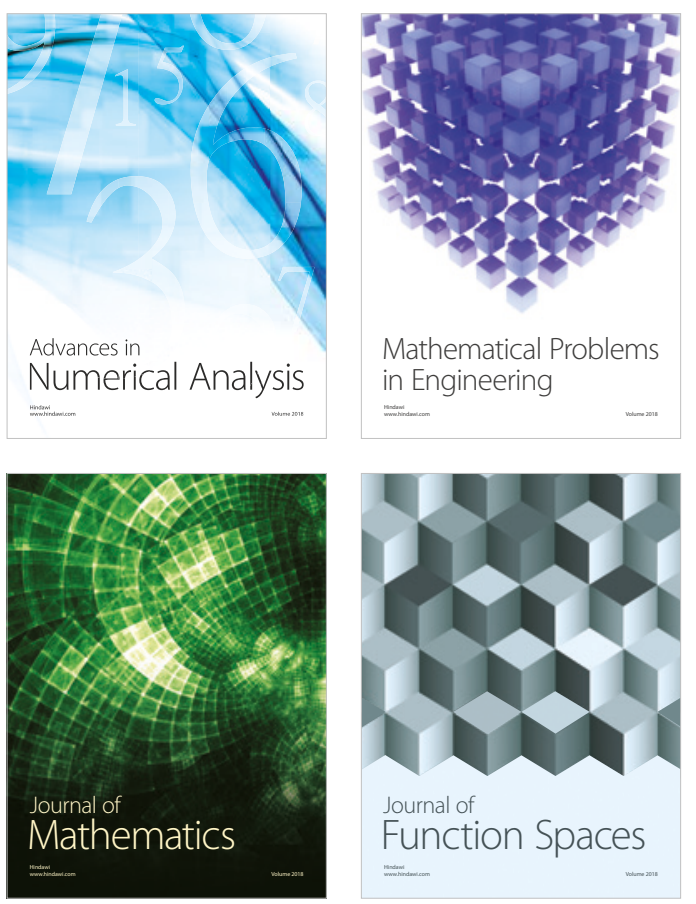

Mathematical Problems in Engineering

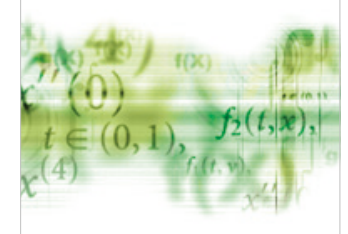

International Journal of

Differential Equations

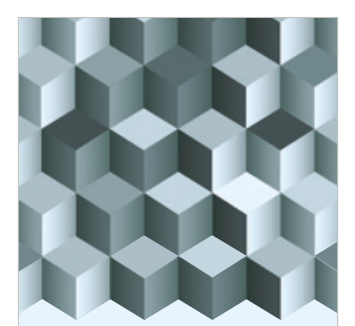

Journal of

Function Spaces

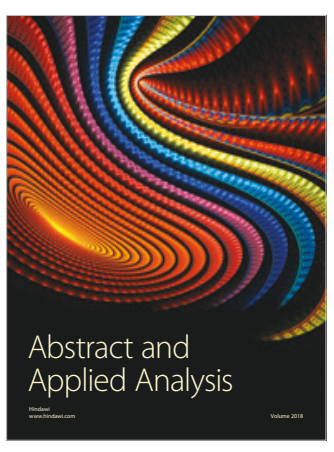

The Scientific

World Journal

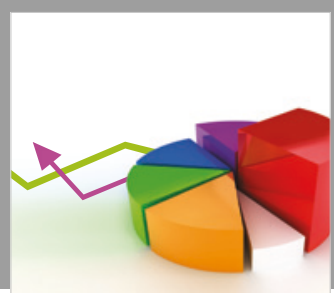

Journal of

Probability and Statistics
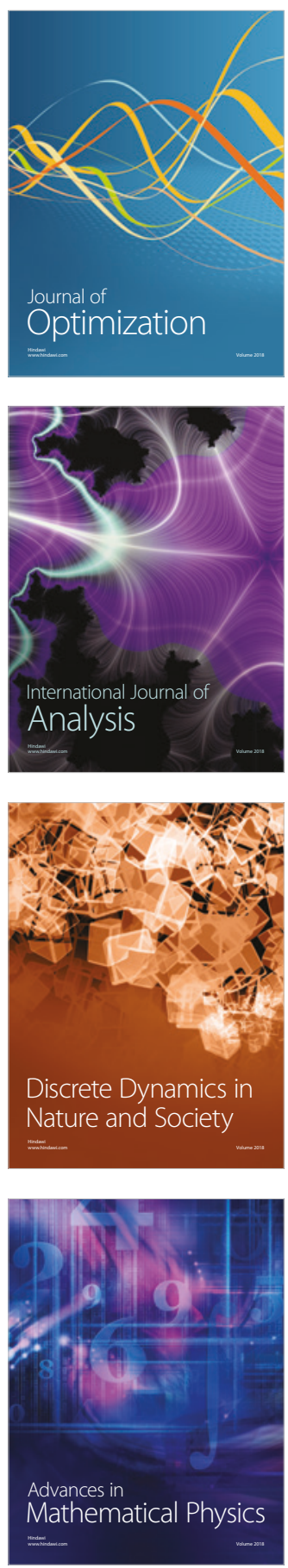